\title{
Serum Cystatin C Level Is Not a Promising Biomarker for Predicting Clinicopathological Characteristics of Bladder Urothelial Tumors
}

\author{
Hui Wang $\mathbb{D}^{1,2}$ Lijian Gao, ${ }^{1,2}$ Cuiyu Meng, ${ }^{3}$ Nengwang Yu, ${ }^{1}$ Feilong Yang, ${ }^{1}$ Cong Zhang, \\ Dawei Li $\mathbb{D}^{1},{ }^{1}$ Lei Yan, ${ }^{1}$ Hainan Liu, ${ }^{1}$ and Zhonghua $\mathrm{Xu}^{1}$ \\ ${ }^{1}$ Department of Urology, Qilu Hospital of Shandong University, Jinan 250012, China \\ ${ }^{2}$ Department of Urology, Dezhou People's Hospital, Dezhou, Shandong Province 253000, China \\ ${ }^{3}$ Department of ICU, Dezhou People's Hospital, Dezhou, Shandong Province 253000, China
}

Correspondence should be addressed to Dawei Li; lidaweimd@aliyun.com

Received 3 November 2017; Accepted 28 December 2017; Published 29 January 2018

Academic Editor: Maria Stangou

Copyright $\odot 2018$ Hui Wang et al. This is an open access article distributed under the Creative Commons Attribution License, which permits unrestricted use, distribution, and reproduction in any medium, provided the original work is properly cited.

\begin{abstract}
The role of cystatin C (Cys-C) in tumorigenesis and progression of bladder urothelial tumors (BUT) is still indefinite. We retrospectively collected the clinical information from the records of 425 BUT patients. Pretreatment serum Cys-C levels were compared across the various groups. Then we subgroup the patients with GFR $\geq 90 \mathrm{mg} / \mathrm{min} / 1.73 \mathrm{~m}^{2}$, to exclude the effects of lower renal function on cystatin C. No statistically significant differences in the levels of serum Cys- $\mathrm{C}$ were found among the tumor characteristics (all $P>0.05$ ). In conclusion, circulating Cys-C was not a reliable predictor for clinicopathological characteristics of BUT patients.
\end{abstract}

\section{Introduction}

By 2020 the estimated incidence of genitourinary (GU) cancers (prostate, bladder, and kidney) will be over 2 million worldwide and responsible for approximately 800,000 deaths [1]. The majority of bladder cancers are transitional cell carcinomas, which account for more than $90 \%$ of all cases, while squamous cell carcinoma and adenocarcinoma are less prevalent [2]. Leiomyomas of the bladder constitute $<0.5 \%$ of all bladder tumors [3]. According to the World Health Organization/International Society of Urological Pathology (WHO/ISUP) classification, bladder urothelial tumors are categorized into three subtypes: papilloma, papillary urothelial neoplasm of low malignant potential (PUNLMP), and carcinoma (bladder urothelial carcinoma, BUC) [4]. Carcinomas are further subcategorized based on the presence of muscular invasion into non-muscle-invasive BUC (NMIBC) (Stage Tis-Ta-T1) and muscle-invasive BUC (MIBC) (Stage T2-T3-T4) [5]. BUC is the ninth most common cancer worldwide. The first economic study of BUC and the first reallife evidence of the current therapeutic algorithm act in the
Italian context. The increase in prevalence requires continuous surveillance and care, resulting in a significant burden on Italian National Health Service, making any improvement to the strategy for diagnosing and treating this disease important to the medical and scientific community [6].

In current clinical practice, the diagnoses of BUT rely on sophisticated instruments and skilled personnel. Cystoscopy and biopsy were performed as a gold method. But this approach brings lots of discomfort to the patient (pain, fear, tension, etc.). Cancer markers may offer the advantages of simplicity, accurately and comfortably. Now, a number of markers have been described. But the performance and robustness of these markers remain unclear.

Cystatin $\mathrm{C}$ is the potent inhibitor of cysteine proteinases [7]. It is abundant in various body tissues and fluids [8]. Previous studies revealed a correlation between high serum levels of cysteine proteinase inhibitors and poor prognosis in malignant melanoma and colorectal cancer [9]. The association of disturbances in the ratio between cysteine proteinases and endogenous inhibitors of cysteine proteinases with malignant progression is well established. 


\section{Materials and Methods}

2.1. Patient Population. A review of medical records was performed for 425 patients who were newly diagnosed with BUT and received surgical management at the Department of Urology, Qilu Hospital of Shandong University, between January 2010 and October 2014. Prior to participation, the following criteria were used to exclude patients:

(1) Coexisting upper tract urothelial tumors or other tumors

(2) History of bladder urothelial tumors and upper tract urothelial tumors

(3) History of cerebral infarction and cerebral hemorrhage within the last 1 month or myocardial infarction within the latest 6 months

(4) Administration of procoagulant or anticoagulant drugs within the past 2 weeks

(5) There is an obvious infection and inflammation.

2.2. Data Collection. Clinical data including patient age at the time of diagnosis, sex, smoking history, painless macroscopic hematuria, routine blood examination results (white blood cell count, platelet count, plasma fibrinogen level, etc.), and other tumor characteristics were obtained from the electronic patient records at our institution. Tumor grade was assessed according to the $1998 \mathrm{WHO} / \mathrm{ISUP}$ classification, and tumor stage was evaluated using the 2002 TNM classification.

\subsection{Cys-C Measurement}

Sample Test and Data Collection. After 8 hours of fasting, $5 \mathrm{~mL}$ of venous blood was obtained from patients with BUT and assayed immediately before clinical treatment. Blood samples were deposited into test tubes containing a clot activator and gel. The circulating Cys-C levels were tested with immunoturbidimetric method using a Roche Cobas 8000 analyzer with reagents purchased from BioSino BioTechnology and Science Inc., Beijing, China. Cys-C levels of $0.51-1.09 \mathrm{mg} / \mathrm{L}$ were defined as normal. The level of SCr was determined using a Roche Cobas 8000 analyzer with reagents purchased from Roche. SCr levels of $62-115 \mu \mathrm{mol} / \mathrm{L}$ were defined as normal. The tests were completed according to the manufacturers' instructions. Clinical data, including age, $\mathrm{SCr}$, and Cys-C, were retrieved from patient files.

We first compared pretreatment serum Cys-C levels among all patients. Subsequently, we divided the patients into two groups according to the glomerular filtration rate $(\mathrm{GFR}<$ $90 \mathrm{~mL} / \mathrm{min} / 1.73 \mathrm{~m}^{2}$ and GFR $\geq 90 \mathrm{~mL} / \mathrm{min} / 1.73 \mathrm{~m}^{2}$ ). Subclass analyses were conducted to exclude the possible effects of renal function on the pretreatment levels of Cys-C. We also analyzed the association of serum Cys-C levels with clinical characteristics of BUT patients. Linear correlations among age, plasma fibrinogen level, and Cys- $\mathrm{C}$ were also evaluated.

We first need to exclude the effect of glomerular filtration rate (GFR) decline on Cys-C. Chronic kidney disease (CKD) was classified into five stages based on the renal glomerular filtration rate (rGFR) values as follows [10]:
Stage $1, \mathrm{rGFR} \geq 90 \mathrm{~mL} / \mathrm{min} / 1.73 \mathrm{~m}^{2}$

Stage $2,60 \mathrm{~mL} / \mathrm{min} / 1.73 \mathrm{~m}^{2} \leq \mathrm{rGFR}<90 \mathrm{~mL} / \mathrm{min} /$ $1.73 \mathrm{~m}^{2}$

Stage $3,30 \mathrm{~mL} / \mathrm{min} / 1.73 \mathrm{~m}^{2} \leq \mathrm{rGFR}<60 \mathrm{~mL} / \mathrm{min} /$ $1.73 \mathrm{~m}^{2}$

Stage $4,15 \mathrm{~mL} / \mathrm{min} / 1.73 \mathrm{~m}^{2} \leq \mathrm{rGFR}<30 \mathrm{~mL} / \mathrm{min} /$ $1.73 \mathrm{~m}^{2}$

Stage $5, \mathrm{rGFR}<15 \mathrm{~mL} / \mathrm{min} / 1.73 \mathrm{~m}^{2}$.

Renal insufficiency was defined as rGFR $<60 \mathrm{~mL} / \mathrm{min} /$ $1.73 \mathrm{~m}^{2}$. Cystatin $\mathrm{C}$ is a sensitive index of renal function injury. A mild kidney injury can lead to a change in cystatin $\mathrm{C}$. In many cases, the Cys- $\mathrm{C}$ has changed before GFR declined. So $\mathrm{rGFR} \geq 90 \mathrm{~mL} / \mathrm{min} / 1.73 \mathrm{~m}^{2}$ was used for grouping patients. The Modification of Diet in Renal Disease (MDRD) equation, initiated in 1999 and based on the serum creatinine level, is still applied clinically after several modifications [11]. Chinese_MDRD (eGFRc-MDRD), $175 \times(\mathrm{Scr})^{-1.234} \times(\text { age })^{-0.179} \times(\times 0.79$ if female $)$, was used to estimate GFR [12].

2.4. Statistical Analysis. The normal distribution of quantitative data in the various groups was assessed by the Kolmogorov-Smirnov test. Normally distributed data were expressed as the mean \pm standard deviation (SD), while the median (range) was reported for data not following a Gaussian distribution. Statistical analyses were accordingly performed using the parametric Student's $t$-test and oneway ANOVA. Qualitative data were reported as numbers and percentages. Linear correlation analyses examine the associations among age, plasma fibrinogen levels, and Cys- $C$ levels. Data were analyzed and processed using the Statistical Package for Social Sciences version 20.0 (SPSS Inc., Chicago, IL, USA). All probabilities were two-tailed and values less than 0.05 were considered statistically significant.

\section{Results}

3.1. Characteristics of Study Population. The study group consisted of patients with BUT consecutively presenting at the Department of Urology, Qilu Hospital of Shandong University. In total, 425 patients conforming to inclusive criteria were eligible for inclusion in the final study. The mean age of patients was $61.93 \pm 13.17$ years, ranging from 19 to 96 . All patients were further grouped according to their levels of GFR. Clinical characteristics of enrolled patients are presented in Table 1.

The present study included 425 patients with newly diagnosed BUT. Among patients with GFR $\geq 90 \mathrm{mg} / \mathrm{min} / 1.73 \mathrm{~m}^{2}$, 263 were men and 58 were women. The mean Cys-C level of this cohort was $0.91 \pm 0.15 \mathrm{mg} / \mathrm{L}$. Among patients with GFR $<90 \mathrm{mg} / \mathrm{min} / 1.73 \mathrm{~m}^{2}, 81$ were men and 23 were women. The mean Cys-C level of this cohort was $1.32 \pm 0.77 \mathrm{mg} / \mathrm{L}$. The mean Cys-C level of patients with GFR $\geq 90 \mathrm{mg} / \mathrm{min} / 1.73 \mathrm{~m}^{2}$ was significantly lower than that of patients with GFR < $90 \mathrm{mg} / \mathrm{min} / 1.73 \mathrm{~m}^{2}(P \leqslant 0.001)$. 
TABLE 1: Clinical characteristics of patients with BUT.

\begin{tabular}{lcccr}
\hline GFR $\left(\mathrm{mg} / \mathrm{min} / 1.73 \mathrm{~m}^{2}\right)$ & Number of patients $(n, \%)$ & Cys-C $(\mathrm{mg} / \mathrm{L})$, \\
mean \pm SD
\end{tabular}

GFR: glomerular filtration rate; Cys-C: cystatin C; P: Student's $t$-test.
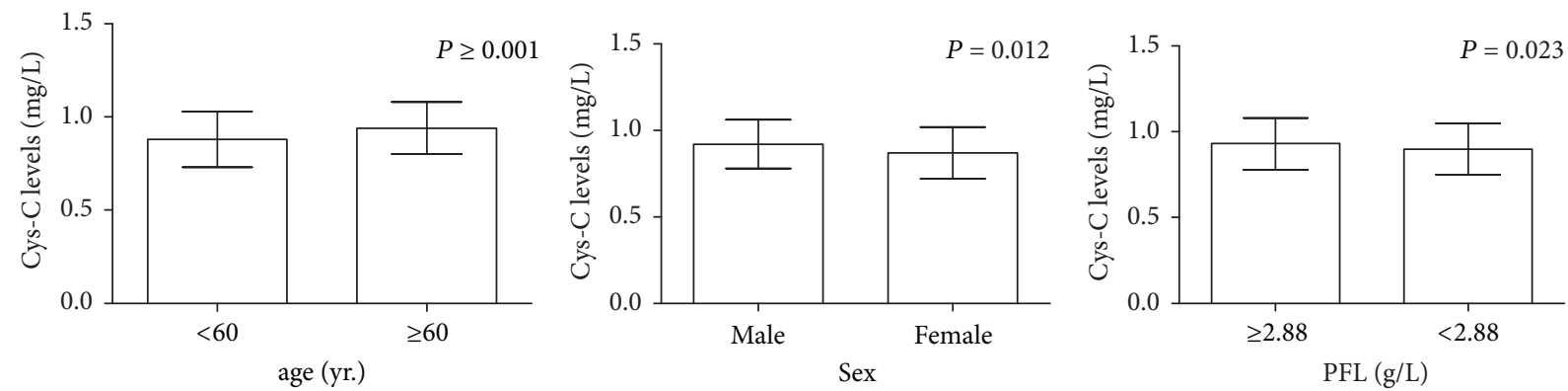

Figure 1: The levels of serum Cys- $C$ in elder BUT patients (more than 60 years) were higher than that in younger patients $(P \leqslant 0.001)$. The levels of serum Cys-C in male BUT patients were higher than in female patients $(P=0.012)$. The mean Cys-C level of patients with $\mathrm{PFL}<$ $2.88 \mathrm{~g} / \mathrm{L}$, which was significantly lower than that of patients with $\mathrm{PFL} \geq 2.88 \mathrm{~g} / \mathrm{L}(P=0.023)$. $P$ : parametric Student's $t$-test.
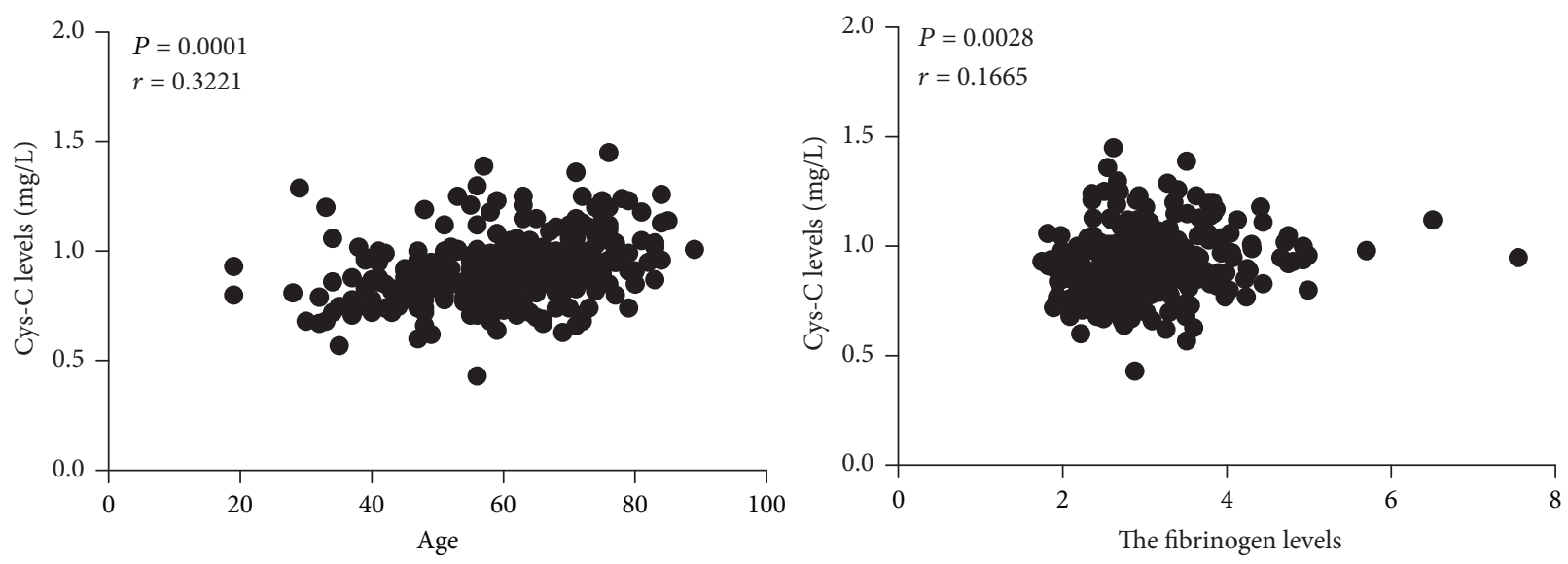

Figure 2: Using linear correlation analyses, there were positive correlations between circulating Cys-C levels, age $(r=0.3221, P=0.0001)$, and PFL ( $r=0.1665, P=0.028)$. P: statistical significance; $r$ : correlation coefficient according to Pearson correlation test.

3.2. Association of Serum Cys-C Levels with Clinical Characteristics of BUT in All Patients Group. We found that the levels of serum Cys-C in elder BUT patients (more than 60 years) were higher than in younger patients $(P=0.013)$. The mean Cys- $C$ level of patients with plasma fibrinogen levels $(P F L)<2.9 \mathrm{~g} / \mathrm{L}$ was significantly lower than that of patients with PFL $\geq 2.9 \mathrm{~g} / \mathrm{L}$ $(P=0.030)$. Clinical characteristics of enrolled patients are presented in Table 2.

3.3. Association of Serum Cys-C Levels with Clinical Characteristics of BUT. Considering the effect of GFR on levels of serum Cys- $C$, the associations between serum Cys- $C$ levels and clinical characteristics of 321 patients with normal GFR ( $\geq 90 \mathrm{mg} / \mathrm{min} / 1.73 \mathrm{~m}^{2}$ ) were further evaluated. BUT patients were stratified accordingly, and these data are presented in Table 3. We found that the levels of serum Cys-C in elder BUT patients (more than 60 years) were higher than that in younger patients $(P \leqslant 0.001)$. The levels of serum Cys$\mathrm{C}$ in male BUT patients were higher than in female patients $(P=0.012)$. The mean Cys-C level of patients with PFL $<$ $2.88 \mathrm{~g} / \mathrm{L}$ was significantly lower than that of patients with PFL $\geq 2.88 \mathrm{~g} / \mathrm{L}(P=0.023)$ (Figure 1$)$.

3.4. Levels of Serum Cys-C Correlate with Age and PFL in BUT Patients with Normal GFR. Using linear correlation analyses, there were positive correlations between circulating Cys-C levels, age $(r=0.3221, P=0.0001)$, and PFL $(r=0.1665$, $P=0.028$ ) (Figure 2).

Moreover, there were insignificant associations between the levels of serum Cys-C and clinical characteristics, such as smoking history, painless macroscopic hematuria, WBC count, PLT count, tumor number, tumor size, and pathological characteristics (all $P>0.05$ ) (Figure 3). 

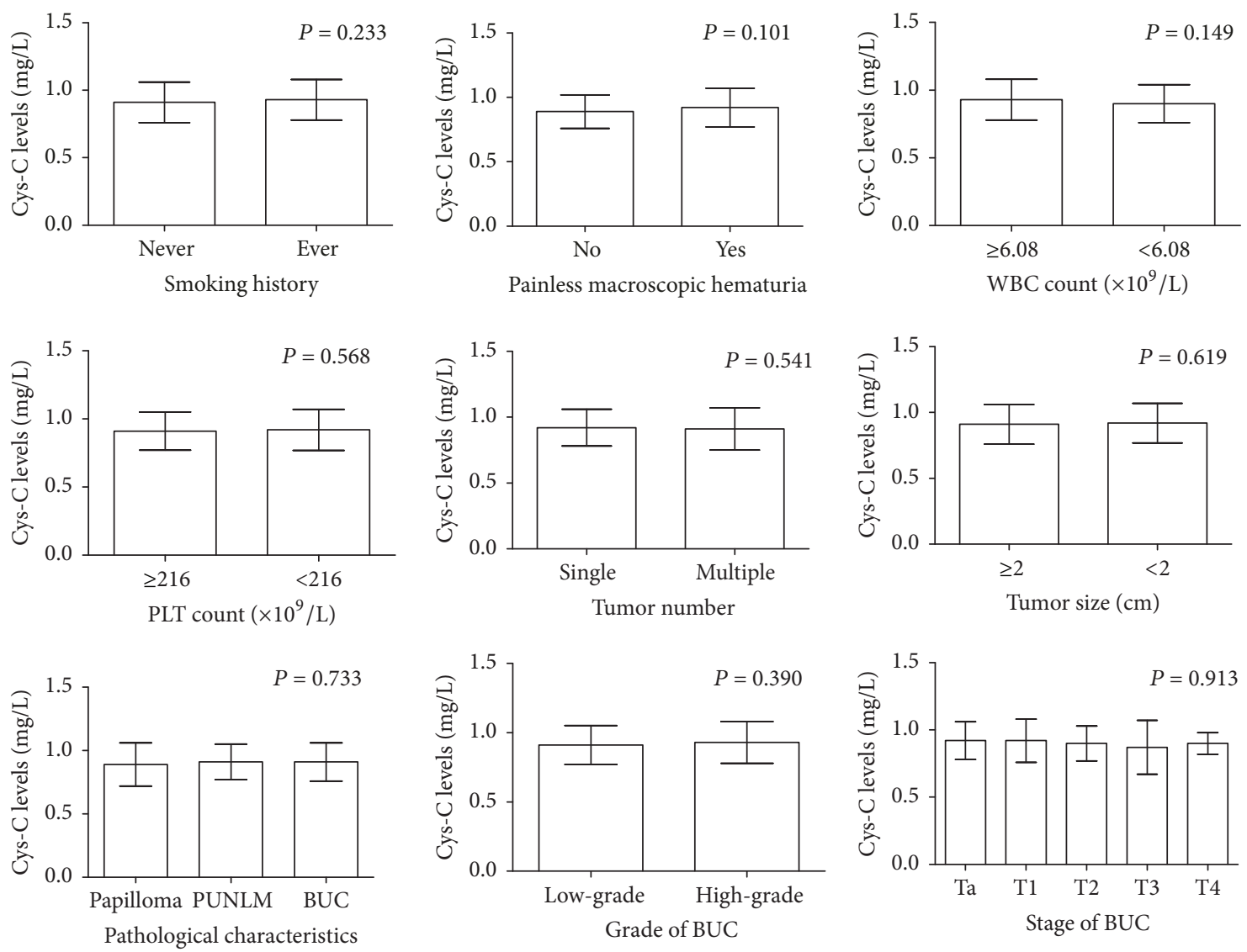

Figure 3: There were insignificant associations between the levels of serum Cys- $\mathrm{C}$ and clinical characteristics, such as smoking history, painless macroscopic hematuria, WBC count, PLT count, tumor number, tumor size, and pathological characteristics (all $P>0.05) . P$ : parametric Student's $t$-test.

\section{Discussion}

In the present study, we examined preoperative Cys-C levels and clinical features of 425 patients with newly diagnosed BUT. Insignificant associations were observed between tumor characteristics and Cys-C levels (tumor number, tumor size, and pathological characteristics) (all $P>0.05$ ). Our results indicate that Cys-C level is not a promising biomarker for predicting pathological outcomes in patients with BUT. To our knowledge, this study is the first to focus on alterations of circulating Cys-C concentrations in patients with BUT using this method. A study published in 2006 indicates that cystatin C concentrations are not directly correlated with the progression of primary bladder carcinomas [13]. The results are consistent with our findings. Our result was in accordance with that from another study focusing on renal cell carcinoma and pancreatic tumors, which excluded the role of serum Cys-C level as possible biomarker [14]. Another study focusing on ovarian cancer indicates the role of serum Cys-C level as possible biomarker [15].

CST3 is located on the short arm of chromosome 20, spans $7.3 \mathrm{~kb}$, contains four exons, encodes a 120-aminoacid active cysteine proteinase inhibitor, and shares several features with housekeeping genes [16]. Cys-C is ubiquitously expressed in nucleated cells [17] in tissues such as the testis, epididymis, seminal vesicle, and prostate [18] and is then secreted into various human fluids to inhibit the activity of cysteine proteases such as papain and cathepsins B, H, K, and L [19].

Cys- $\mathrm{C}$ is considered to function as a $\mathrm{p} 53$-inducible tumor suppressor and apoptotic mediator that negatively regulates cathepsin L activity during carcinogenesis [20]. Cys-C is believed to play a key role in the tumor suppressive function of p53 [20], as well as in extracellular protein homeostasis. An imbalance between Cys-C and cysteine proteinases has been discovered in the pathogenesis of a broad spectrum of diseases [21]. But the diagnostic role of Cys- $\mathrm{C}$ has been dismissed in some cancers, such as renal cell carcinoma and pancreatic tumors [14]. Cys-C was also found to modulate the invasion of prostate cancer cells by means of the androgen receptor and MAPK/Erk2 pathways [22]. Cys-C is also a marker for inflammation [23] and infection [21].

The mean Cys-C level of patients with GFR $\geq 90 \mathrm{mg} / \mathrm{min} /$ $1.73 \mathrm{~m}^{2}$ was significantly lower than that of patients with GFR $<90 \mathrm{mg} / \mathrm{min} / 1.73 \mathrm{~m}^{2}$. Cys-C is a cationic, nonglycosylated protein with a molecular mass of $13 \mathrm{kDa}$. It is ubiquitously expressed in all nucleated cells, widely distributed in human biological fluids [17], freely filtered through renal glomeruli, 
TABLE 2: The level of serum Cys-C in whole BUT patients.

\begin{tabular}{|c|c|c|c|}
\hline Parameters & Number of patients & $\begin{array}{c}\text { Cys-C } \\
\text { levels }(\mathrm{mg} / \mathrm{L}, \text { mean } \pm \mathrm{SD})\end{array}$ & $P$ \\
\hline Age & & & 0.013 \\
\hline$<60$ yr. & 167 & $0.95 \pm 0.57$ & \\
\hline$\geq 60 \mathrm{yr}$ & 258 & $1.05 \pm 0.31$ & \\
\hline Sex & & & 0.704 \\
\hline Male & 344 & $1.02 \pm 0.45$ & \\
\hline Female & 81 & $1.00 \pm 0.37$ & \\
\hline Smoking history & & & 0.153 \\
\hline Never & 277 & $0.99 \pm 0.30$ & \\
\hline Ever & 148 & $1.05 \pm 0.62$ & \\
\hline Painless macroscopic hematuria & & & 0.928 \\
\hline No & 89 & $1.00 \pm 0.34$ & \\
\hline Yes & 336 & $1.01 \pm 0.46$ & \\
\hline WBC count ${ }^{\mathrm{a}}$ & & & 0.553 \\
\hline$<6.1 \times 10^{9} / \mathrm{L}$ & 209 & $1.03 \pm 0.56$ & \\
\hline$\geq 6.1 \times 10^{9} / \mathrm{L}$ & 216 & $1.00 \pm 0.27$ & \\
\hline PLT count $^{\mathrm{a}}$ & & & 0.525 \\
\hline$<213 \times 10^{9} / \mathrm{L}$ & 212 & $1.03 \pm 0.33$ & \\
\hline$\geq 213 \times 10^{9} / \mathrm{L}$ & 213 & $1.00 \pm 0.52$ & \\
\hline $\mathrm{PFL}^{\mathrm{a}}$ & & & 0.030 \\
\hline$<2.9 \mathrm{~g} / \mathrm{L}$ & 200 & $0.95 \pm 0.25$ & \\
\hline$\geq 2.9 \mathrm{~g} / \mathrm{L}$ & 224 & $1.07 \pm 0.55$ & \\
\hline Tumor number & & & 0.095 \\
\hline Single & 291 & $0.98 \pm 0.25$ & \\
\hline Multiple & 134 & $1.08 \pm 0.68$ & \\
\hline Tumor size $^{\mathrm{a}}$ & & & 0.378 \\
\hline$<2 \mathrm{~cm}$ & 124 & $0.98 \pm 0.29$ & \\
\hline$\geq 2 \mathrm{~cm}$ & 299 & $1.02 \pm 0.49$ & \\
\hline Pathological characteristics & & & 0.156 \\
\hline Papilloma & 27 & $0.94 \pm 0.18$ & \\
\hline PUNLMP & 67 & $0.931 \pm 0.16$ & \\
\hline BUC & 331 & $1.03 \pm 0.48$ & \\
\hline Grade & & & 0.836 \\
\hline Low-grade & 180 & $1.03 \pm 0.60$ & \\
\hline High-grade & 151 & $1.04 \pm 0.29$ & \\
\hline Stage & & & 0.783 \\
\hline $\mathrm{Ta}$ & 178 & $1.03 \pm 0.59$ & \\
\hline $\mathrm{T} 1$ & 91 & $1.05 \pm 0.37$ & \\
\hline $\mathrm{T} 2$ & 34 & $0.98 \pm 0.20$ & \\
\hline $\mathrm{T} 3$ & 17 & $0.97 \pm 0.22$ & \\
\hline $\mathrm{T} 4$ & 11 & $1.18 \pm 0.32$ & \\
\hline
\end{tabular}

Continuous variables are expressed as median ${ }^{\mathrm{a}}$. Bold values are statistically significant $(P<0.05)$. PUNLMP: papillary urothelial neoplasm of low malignant potential; BUC: bladder urothelial carcinoma; WBC: white blood cell; PLT: platelet; PFL: plasma fibrinogen levels.

and uniquely and almost completely reabsorbed and catabolized in the proximal tubules [24]. Therefore, its classic role as a sensitive marker for renal function has been extensively studied [24] and further confirmed in a meta-analysis.

In the whole BUT patients, we found that the levels of serum Cys-C in elder BUT patients (more than 60 years) were higher than in younger patients $(P=0.013)$. The mean
Cys-C level of patients with PFL $<2.9 \mathrm{~g} / \mathrm{L}$ was significantly lower than that of patients with plasma fibrinogen levels $\geq$ $2.9 \mathrm{~g} / \mathrm{L}(P=0.030)$. In the subgroup of bladder urothelial tumors patients with normal GFR, we also found that the levels of serum Cys-C in elder BUT patients (more than 60 years) were higher than in younger patients $(P \leqslant 0.001)$. The mean Cys-C level of patients with $\mathrm{PFL}<2.88 \mathrm{~g} / \mathrm{L}$ was 
TABLE 3: The level of serum Cys-C in BUT patients with normal GFR.

\begin{tabular}{|c|c|c|c|}
\hline Parameters & Number of patients & $\begin{array}{c}\text { Cys-C } \\
\text { levels }(\mathrm{mg} / \mathrm{L}, \text { mean } \pm \mathrm{SD})\end{array}$ & $P$ \\
\hline Age & & & 0.001 \\
\hline$<60 \mathrm{yr}$ & 144 & $0.88 \pm 0.15$ & \\
\hline$\geq 60 \mathrm{yr}$ & 177 & $0.94 \pm 0.14$ & \\
\hline Sex & & & 0.012 \\
\hline Male & 263 & $0.92 \pm 0.14$ & \\
\hline Female & 58 & $0.87 \pm 0.15$ & \\
\hline Smoking history & & & 0.233 \\
\hline Never & 204 & $0.91 \pm 0.15$ & \\
\hline Ever & 117 & $0.93 \pm 0.15$ & \\
\hline Painless macroscopic hematuria & & & 0.101 \\
\hline No & 59 & $0.89 \pm 0.13$ & \\
\hline Yes & 262 & $0.92 \pm 0.15$ & \\
\hline $\mathrm{WBC}_{\text {count }}{ }^{\mathrm{a}}$ & & & 0.149 \\
\hline$<6.08 \times 10^{9} / \mathrm{L}$ & 160 & $0.90 \pm 0.14$ & \\
\hline$\geq 6.08 \times 10^{9} / \mathrm{L}$ & 161 & $0.93 \pm 0.15$ & \\
\hline PLT count ${ }^{\mathrm{a}}$ & & & 0.568 \\
\hline$<216 \times 10^{9} / \mathrm{L}$ & 160 & $0.92 \pm 0.15$ & \\
\hline$\geq 216 \times 10^{9} / \mathrm{L}$ & 161 & $0.91 \pm 0.14$ & \\
\hline $\mathrm{PFL}^{\mathrm{a}}$ & & & 0.023 \\
\hline$<2.88 \mathrm{~g} / \mathrm{L}$ & 161 & $0.90 \pm 0.15$ & \\
\hline$\geq 2.88 \mathrm{~g} / \mathrm{L}$ & 160 & $0.93 \pm 0.15$ & \\
\hline Tumor number & & & 0.541 \\
\hline Single & 229 & $0.92 \pm 0.13$ & \\
\hline Multiple & 92 & $0.91 \pm 0.16$ & \\
\hline Tumor size $^{\mathrm{a}}$ & & & 0.619 \\
\hline$<2 \mathrm{~cm}$ & 101 & $0.91 \pm 0.15$ & \\
\hline$\geq 2 \mathrm{~cm}$ & 218 & $0.92 \pm 0.15$ & \\
\hline Pathological characteristics & & & 0.733 \\
\hline Papilloma & 21 & $0.89 \pm 0.17$ & \\
\hline PUNLMP & 60 & $0.91 \pm 0.14$ & \\
\hline BUC & 240 & $0.92 \pm 0.15$ & \\
\hline Grade & & & 0.390 \\
\hline Low-grade & 141 & $0.91 \pm 0.14$ & \\
\hline High-grade & 99 & $0.93 \pm 0.15$ & \\
\hline Stage & & & 0.913 \\
\hline $\mathrm{Ta}$ & 140 & $0.92 \pm 0.79$ & \\
\hline $\mathrm{T} 1$ & 62 & $0.92 \pm 0.16$ & \\
\hline $\mathrm{T} 2$ & 27 & $0.90 \pm 0.13$ & \\
\hline T3 & 7 & $0.87 \pm 0.20$ & \\
\hline $\mathrm{T} 4$ & 4 & $0.90 \pm 0.08$ & \\
\hline
\end{tabular}

Continuous variables are expressed as median ${ }^{\mathrm{a}}$. Bold values are statistically significant $(P<0.05)$. PUNLMP: papillary urothelial neoplasm of low malignant potential; BUC: bladder urothelial carcinoma; WBC: white blood cell; PLT: platelet; PFL: plasma fibrinogen levels.

significantly lower than that of patients with $\mathrm{PFL} \geq 2.88 \mathrm{~g} / \mathrm{L}$ $(P=0.023)$. Even more, the levels of serum Cys- $\mathrm{C}$ in male BUT patients were higher than that in female patients $(P=0.012)$. A lot of research suggests that age-related reductions in the glomerular filtration rate (GFR) [25] lead to age-dependent increases in the concentrations of serum Cys-C $[26,27]$. But in our study, in the group of GFR $\geq 90 \mathrm{~mL} / \mathrm{min} / 1.73 \mathrm{~m}^{2}$, the concentrations of serum Cys-C also have an age-dependent increase, indicating that agedependent increases in the concentrations of serum Cys$\mathrm{C}$ just partly depended on age-related reductions in the glomerular filtration rate (GFR). Using linear correlation analyses, there were positive correlations between circulating Cys- $C$ levels, age $(r=0.3221, P=0.0001)$, and plasma 
fibrinogen levels $(r=0.1665, P=0.028)$. Sex is also an independent factor affecting the concentrations of serum Cys-C excluding the effect of glomerular filtration rate (GFR) decline.

There were insignificant associations between the levels of serum Cys- $\mathrm{C}$ and clinical characteristics, such as smoking history and painless macroscopic hematuria. BUC is one of the most common malignancies in the industrialized world, mainly caused by smoking and occupational exposure to chemicals. The favorable prognosis of early stage bladder cancer underscores the importance of early detection for the treatment of this disease. The high recurrence rate of this malignancy also highlights the need for close postdiagnosis monitoring of bladder cancer patients [28].

In conclusion, no statistically significant differences in the levels of serum Cys-C were found among the tumor characteristics (tumor number, tumor size, and pathological characteristics (all $P>0.05)$ ). Circulating Cys-C was not a potential marker for BUC tumorigenesis and was not a reliable predictor for clinicopathological characteristics of BUC patients.

\section{Conflicts of Interest}

The authors declare that they have no conflicts of interest.

\section{Authors' Contributions}

Hui Wang was responsible for design of study, date collection, statistical analysis, and manuscript writing. Lijian Gao was responsible for design of study, date collection, statistical analysis, and manuscript writing. Cuiyu Meng was responsible for design of study, date collection, and date analysis. Nengwang Yu was responsible for design of study and manuscript revising. Feilong Yang was responsible for design of study, date collection, and date analysis. Cong Zhang was responsible for design of study, date collection, and date analysis. Dawei Li was responsible for design of study, date collection, date analysis, and manuscript revising. Lei Yan was responsible for design of study and manuscript revising. Hainan Liu was responsible for design of study and manuscript revising. Zhonghua $\mathrm{Xu}$ was responsible for design of study and manuscript revising. Hui Wang and Lijian Gao contributed equally to the manuscript.

\section{Acknowledgments}

This study was supported by financial grants from the National Natural Science Foundation of China (Grant nos. 81502213 and 81372335) (https://isisn.nsfc.gov.cn/egrantweb/), the Natural Science Foundation of Shandong Province (Grant no. 2015ZRE27283) (http://jihlx.sdstc .gov.cn/STDPMS/ZR/Default.aspx), and the Focused Research and Development Program of Shandong Province (Grant nos. 2016GSF201171 and 2017GSF18130) (http://jihlx .sdstc.gov.cn/STDPMS/GG/Default.aspx).

\section{References}

[1] S. Y. Lin, J. A. Linehan, T. G. Wilson, and D. S. B. Hoon, "Emerging utility of urinary cell-free nucleic acid biomarkers for prostate, bladder, and renal cancers," European Urology Focus, vol. 3, no. 2-3, pp. 265-272, 2017.

[2] D. S. Kaufman, W. U. Shipley, and A. S. Feldman, "Bladder cancer," The Lancet, vol. 374, no. 9685, pp. 239-249, 2009.

[3] J. E. Mendes, A. V. Ferreira, S. Coelho, and C. Gil, "Bladder leiomyoma," Urology Annals, vol. 9, no. 3, pp. 275-277, 2017.

[4] J. I. Epstein, M. B. Amin, and V. R. Reuter, "The World Health Organization/International Society of Urological Pathology consensus classification of urothelial (transitional cell) neoplasms of the urinary bladder," The American Journal of Surgical Pathology, vol. 22, no. 12, pp. 1435-1448, 1998.

[5] J. Liu, D. Li, L. Cao et al., "Elevated preoperative plasma fibrinogen level is an independent predictor of malignancy and advanced stage disease in patients with bladder urothelial tumors," International Journal of Surgery, vol. 36, pp. 249-254, 2016.

[6] C. Gerace, F. Montorsi, R. Tambaro et al., "Cost of illness of urothelial bladder cancer in Italy," ClinicoEconomics and Outcomes Research, vol. 9, pp. 433-442, 2017.

[7] P. Lindahl, M. Nycander, K. Ylinenjarvi, E. Pol, and I. Bjork, "Characterization by rapid-kinetic and equilibrium methods of the interaction between $\mathrm{N}$-terminally truncated forms of chicken cystatin and the cysteine proteinases papain and actinidin," Biochemical Journal, vol. 286, no. 1, pp. 165-171, 1992.

[8] A. J. Barrett, H. Fritz, A. Grubb et al., "Nomenclature and classification of the proteins homologous with the cysteineproteinase inhibitor chicken cystatin," Biochemical Journal, vol. 236, no. 1, article 312, 1986.

[9] J. Kos, M. Krašovec, N. Cimerman, H. J. Nielsen, I. J. Christensen, and N. Brünner, "Cysteine proteinase inhibitors stefin $A$, stefin B, and cystatin C in sera from patients with colorectal cancer: Relation to prognosis," Clinical Cancer Research, vol. 6, no. 2, pp. 505-511, 2000.

[10] K. M. Andrassy, "Comments on 'KDIGO 2012 clinical practice guideline for the evaluation and management of chronic kidney disease," Kidney International, vol. 84, no. 3, pp. 622-623, 2013.

[11] A. S. Levey, J. P. Bosch, J. B. Lewis, T. Greene, N. Rogers, and D. Roth, "A more accurate method to estimate glomerular filtration rate from serum creatinine: a new prediction equation. Modification of Diet in Renal Disease Study Group," Annals of Internal Medicine, vol. 130, no. 6, pp. 461-470, 1999.

[12] Y. Ma, L. Zuo, J. Chen et al., "Modified glomerular filtration rate estimating equation for Chinese patients with chronic kidney disease," Journal of the American Society of Nephrology, vol. 17, no. 10, pp. 2937-2944, 2006.

[13] C. Tokyol, T. Köken, M. Demirbas et al., "Expression of cathepsin D in bladder carcinoma: Correlation with pathological features and serum cystatin C levels," TUMORI, vol. 92, no. 3, pp. 230-235, 2006.

[14] B. Jacobsson, H. Lignelid, and U. S. R. Bergerheim, "Transthyretin and cystatin $\mathrm{C}$ are catabolized in proximal tubular epithelial cells and the proteins are not useful as markers for renal cell carcinomas," Histopathology, vol. 26, no. 6, pp. 559-564, 1995.

[15] E. A. Gashenko, V. A. Lebedeva, I. V. Brak, E. A. Tsykalenko, G. V. Vinokurova, and T. A. Korolenko, "Evaluation of serum procathepsin $\mathrm{B}$, cystatin $\mathrm{B}$ and cystatin $\mathrm{C}$ as possible biomarkers 
of ovarian cancer," International Journal of Circumpolar Health, vol. 72, no. 1, 2013.

[16] M. Abrahamson, I. Olafsson, A. Palsdottir et al., "Structure and expression of the human cystatin C gene," Biochemical Journal, vol. 268, no. 2, pp. 287-294, 1990.

[17] M. A. Ferguson and S. S. Waikar, "Established and emerging markers of kidney function," Clinical Chemistry, vol. 58, no. 4, pp. 680-689, 2012.

[18] T. Jiborn, M. Abrahamson, H. Wallin et al., "Cystatin C is highly expressed in the human male reproductive system," Journal of Andrology, vol. 25, no. 4, pp. 564-572, 2004.

[19] R. Janowski, M. Kozak, E. Jankowska et al., "Human cystatin $\mathrm{C}$, an amyloidogenic protein, dimerizes through threedimensional domain swapping," Nature Structural Biology, vol. 8, no. 4, pp. 316-320, 2001.

[20] J. Mori, C. Tanikawa, Y. Funauchi, P. H. Y. Lo, Y. Nakamura, and K. Matsuda, "Cystatin C as a p53-inducible apoptotic mediator that regulates cathepsin L activity," Cancer Science, vol. 107, no. 3, pp. 298-306, 2016.

[21] Y.-T. Lee, S.-C. Chen, L.-Y. Shyu et al., "Significant elevation of plasma cathepsin B and cystatin $\mathrm{C}$ in patients with communityacquired pneumonia," Clinica Chimica Acta, vol. 413, no. 5-6, pp. 630-635, 2012.

[22] B. Wegiel, T. Jiborn, M. Abrahamson et al., "Cystatin C is downregulated in prostate cancer and modulates invasion of prostate cancer cells via MAPK/Erk and androgen receptor pathways," PLoS ONE, vol. 4, no. 11, Article ID e7953, 2009.

[23] R. Lertnawapan, A. Bian, Y. H. Rho et al., "Cystatin C is associated with inflammation but not atherosclerosis in systemic lupus erythematosus," Lupus, vol. 21, no. 3, pp. 279-287, 2012.

[24] H. Nishikawa, Y. Ozaki, T. Nakanishi et al., "The role of cathepsin B and cystatin $\mathrm{C}$ in the mechanisms of invasion by ovarian cancer," Gynecologic Oncology, vol. 92, no. 3, pp. 881886, 2004.

[25] J. Helmersson-Karlqvist, M. Flodin, L.-O. Hansson, and A. Larsson, "The age related association is more pronounced for cystatin C estimated GFR than for creatinine estimated GFR in primary care patients," Clinical Biochemistry, vol. 46, no. 16-17, pp. 1761-1763, 2013.

[26] L. Norlund, A. Grubb, G. Fex et al., "The increase of plasma homocysteine concentrations with age is partly due to the deterioration of renal function as determined by plasma cystatin C," Clinical Chemistry and Laboratory Medicine, vol. 36, no. 3, pp. 175-178, 1998.

[27] G. Ohara, K. Miyazaki, K. Kurishima et al., "Serum levels of cystatin C in elderly lung cancer patients," Oncology Letters, vol. 3, no. 2, pp. 303-306, 2012.

[28] J. T. Ark, J. R. Alvarez, T. Koyama et al., "Variation in the Diagnostic Evaluation among Persons with Hematuria: Influence of Gender, Race and Risk Factors for Bladder Cancer," The Journal of Urology, vol. 198, no. 5, pp. 1033-1038, 2017. 


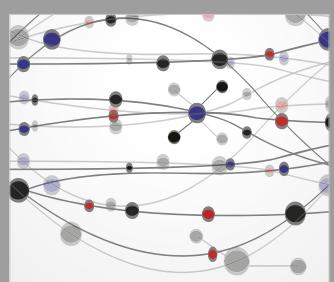

The Scientific World Journal
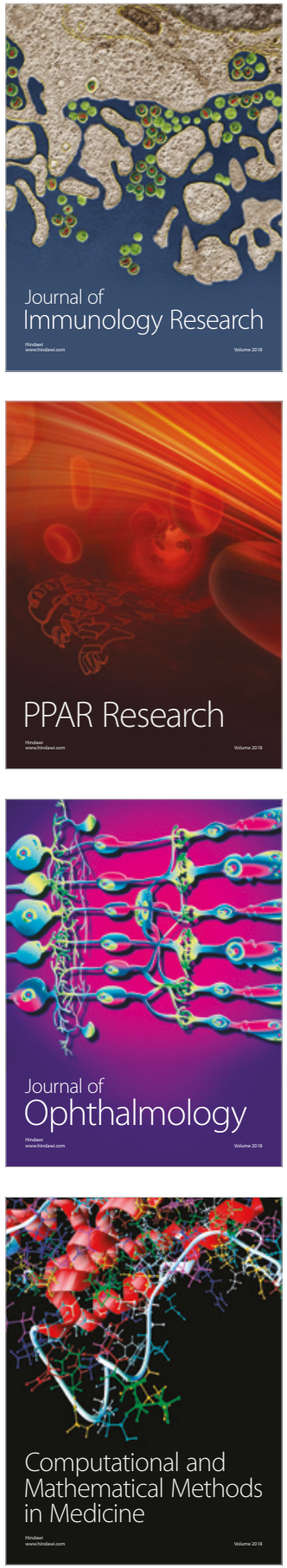

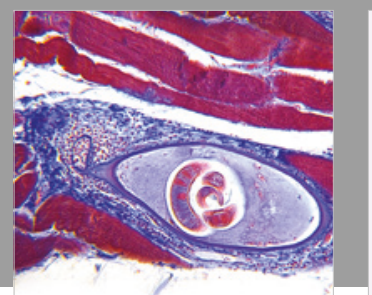

Gastroenterology Research and Practice

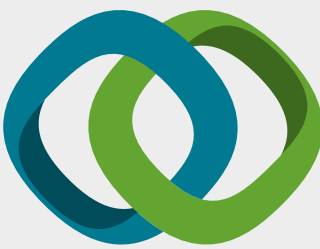

\section{Hindawi}

Submit your manuscripts at

www.hindawi.com
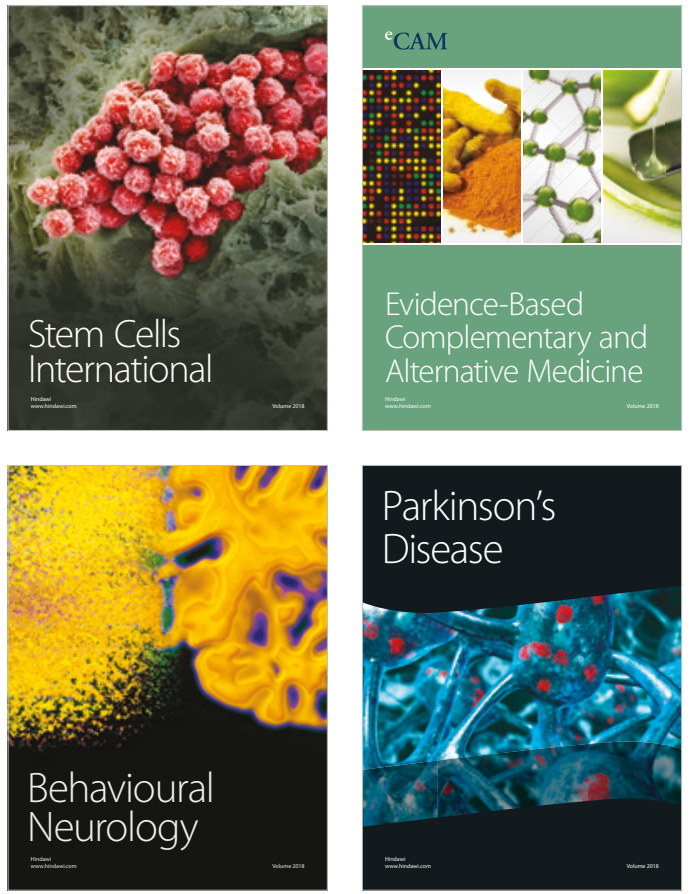

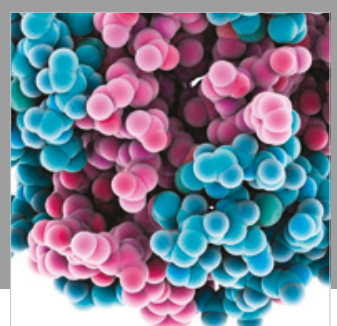

ournal of

Diabetes Research

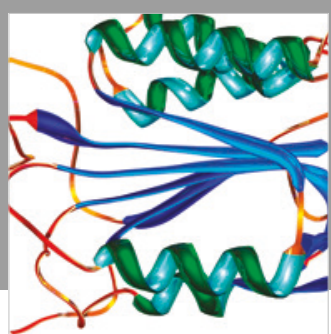

Disease Markers
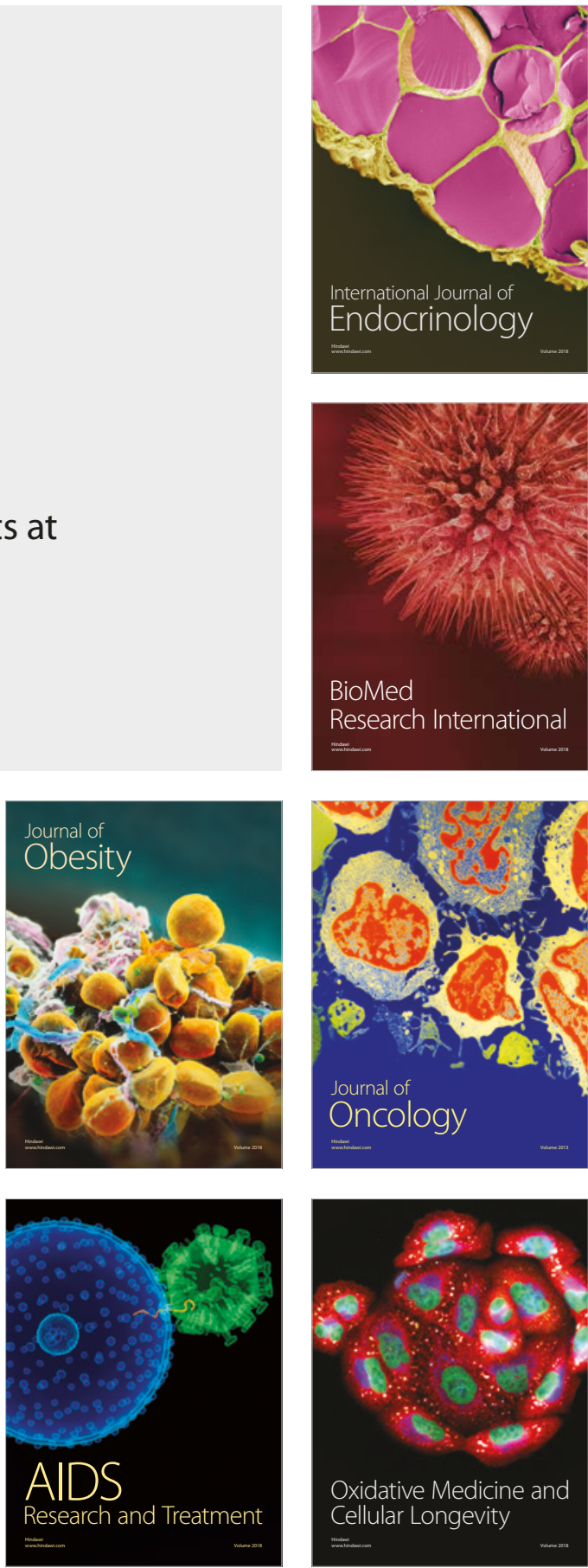